[Note: pagination of Tillson's forthcoming paper in TRE follows that in his typescript. I have flagged it in bold, as in (p.[2]).]

\title{
Moral education and the limits of rationality: a reply to John Tillson
}

John White

UCL Institute of Education

This short paper began as a way of putting the record straight about a mistake that John Tillson made about my views on moral education in his recent 'The Problem of Rational Moral Enlistment' (TRE •). I have now added to this some more general comments on Tillson's approach.

Tillson, like Michael Hand (2014) whose paper he also discusses, is interested in what rational grounds can be offered to children for recognizing the requirements of morality, ie for their 'moral enlistment' in Tillson's strangely military-sounding term. While sharing 'a broadly Handian conception of education', he disagrees with Hand's foundationalist approach to moral education which sees some moral standards as rationally grounded in 'the amelioration of "breakdown in cooperation and outbreaks of conflict' within social groups; and puts in its place a different kind of rational grounding, namely an appeal to reflective equilibrium that draws on work by Ben Spiecker and Jan Steutel (2001).

First the mistake about my views. In my 'Moral education and education in altruism. Two replies to Michael Hand' (White 2016), I argued against Hand's foundationalist approach mentioned above. Hand's position is that those involved in moral education should, among other tasks, bring children to accept the justifiability of those moral standards that are incontrovertible like, for example, prohibitions on stealing and causing harm and the prescription to treat others fairly. The justification is founded on the amelioration of social breakdown mentioned above - an argument indebted to $\mathrm{H} L \mathrm{~A}$ Hart and David Copp. Only when educators teach in this way can moral education be a rational rather than an indoctrinatory enterprise.

As well as doubting how far young children are able to grasp the theoretical argument about social breakdown and also pointing out the familiar 'free rider' problem if they do grasp it, I also asked whether it is necessary for them to grasp it in order to receive a sound moral education. My line of thought is a familiar one in the ethical tradition associated with Hume and expressed in our own age in the writings of Bernard Williams, Simon Blackburn, Joseph Raz and others. It is that at the bedrock of morality is that we should care for people's (and perhaps some animals') well-being. We can appeal to this in justifying non-bedrock injunctions - that one ought not to lie, steal etc - but we cannot provide arguments for this 
bedrock itself. We bring children up to care for their own and others' well-being by encouraging their inclinations in that direction: justification does not come into the picture.

All this is necessary background to my problem with Tillson's representation - or, rather, misrepresentation - of my position. He writes that

whereas Hand is a rationalist, seeking reasons for moral commitment, White eschews reasons, preferring to 'ground' moral commitment in sentiment:

On this view, which I favour, caring for people's well-being is something we bring children up to feel positively about. Hand may, of course, agree with this as something we should do at a pre-rational stage of moral education, provided that good reasons are supplied later. Where I depart from him is in removing the proviso. Coming to care is all the bedrock needed (White 2016: 454-455).

Contra White, I do not think that moral education simply boils down to a matter of our bringing up children to care about other people's well-being if we ourselves happen to care about other people's well-being, but to an additional fact that we should care about one another's well-being.

Is it true that I 'eschew reasons' for moral commitment as Tillson claims in his opening sentence? Not in general: only in relation to the bedrock. There is a good reason why we should not lie or steal. Doing these things harms people, is a threat to their well-being. We should not do them if we care for this.

Turning to Tillson's closing sentence, I simply don't ascribe to the position he attributes to me. When he says that 'we should care about one another's well-being', I agree with him and would want all those being morally educated to agree with him. Whether this is a 'fact' as implied in Tillson's calling it 'an additional fact' is a further matter. My Humean position would lead me to say that it is not something capable of truth or falsity. It is subjective in that sense, but not in the further, individualist, sense that it is something which I feel committed to while others may feel differently. I see the bedrock as an intersubjective commitment - as something which all human beings should ideally be brought up to embrace as the basis of our personal, moral and political life.

This means that Tillson is just wrong in implying that I think 'that moral education simply boils down to a matter of our bringing up children to care about other people's well-being if we ourselves happen to care about other people's well-being'. Bringing children up to care about others' well-being does not depend on parents' or teachers' happening to care about this - as if it were perfectly all right for them not to do so if what they happened to care about was something different. Educators, like the rest of us, should care about others' wellbeing and want children to do so too.

Could it be partly through misreading my text that Tillson has got me so wrong? When I say in the passage he quotes from me that 'where I depart from [Hand] is in removing the proviso', he may be taking me as implying that good reasons don't have any place at any 
stage of moral education. This would make sense of Tillson's several remarks in the paragraph last quoted from him to the effect that I see moral education as an arbitrary matter: phrases, for instance, like 'happen to care' (mentioned above), as well as 'the roulette of values formation', 'switch all of our values by caprice', 'merely reflect arbitrary preferences'. It would also explain why he implies in the following paragraph that I could not support teaching evolution as a better-grounded theory than creationism.

In fact, however, I did not mean that good reasons don't have any place at any stage of moral education. What I meant - and took it that the context would make this clear enough - was that good reasons for caring about people's well-being are out of the question. As I illustrate in my paper, children should be taught that there are good reasons for not lying to people or stealing from them, etc. There are, I scarcely need to add, innumerable places beyond this fairly basic level where moral education has to do with the rational assessment of moral claims.

I turn to more general comments on Tillson's approach to moral education. Some of these also apply to Michael Hand's position. Like Hand, Tillson is a rationalist about moral education, but seeks its rational underpinning by 'appealing to reflective equilibrium rather than ethical foundationalism' (p.[2]). Saying that both Hand and Tillson are rationalists goes further than saying that they both see a place for moral educators to engage with learners in discussing reasons for moral claims. As I indicated at the end of the last section, I myself see a place for this, although my approach to moral education is very different from both of theirs.

Where they go further is in invoking a justificatory ethical theory when looking for rational grounds that can be offered to children as part of their moral education. Hand advocates helping children to understand the foundational Hart/Copp justification in terms of preventing social breakdown. Tillson says that 'compelling arguments making use of reflective equilibrium can be formulated and put to children in educational contexts' (p.[15]). Leaving Hand's position on one side since I have discussed it in White (2016), what are we to make of Tillson's view? The example he gives of invoking reflective equilibrium begins with a teacher asking a child who has kicked another in the dinner queue whether it would be all right if the other kicked him. If the answer is no, the argument moves to the issue of whether there is a relevant difference between the two cases and brings in the principle 'do not kick people' or, more generally, 'do not harm' them.

My worry here is whether this is indeed an example of invoking reflective equilibrium. It does, it is true, bring together particular cases and general principles, but it does this with the intention of helping a child to become clearer about something on the way to changing his behaviour. This is a practical, not a theoretical, enterprise. The philosophical contexts from which Tillson has drawn in his discussion of reflective equilibrium treat the latter as a philosophical theory seen as providing a justificatory basis for moral positions. This is true both of Rawls, as is well known, and of Spiecker and Steutel. These rely on reflective 
equilibrium in 'justifying an ethical conception of children's sexual rights' (Spiecker and Steutel (2001: 30). This is a theoretical, not a practical enterprise.

The home of reflective equilibrium is in ethical theory. How far it makes sense to apply it to a practical task like teaching morality is doubtful. Tillson's case of the child kicking rings true enough as a possible interchange between a teacher and a pupil. it would ring even truer, perhaps, knowing what some children are likely to say, if the culprit answered 'Yes (it would be all right if he kicked me)'; but this would make it harder for the philosophically-minded teacher in the story to move on to the issue of relevant differences and principles beyond it. Let us concede to Tillson, however, that his example is a possible one. We can imagine many other such interchanges. They are part of informal moral upbringing.

In more formal settings we are also familiar with class discussion about particular morallyrelevant incidents or practices. The topic may be, for instance, whether we should all be vegetarians. Here, too, the teacher can lead children into deeper waters, showing them among other things where rules and principles come into the frame and where they might conflict. But it is misleading to call such things examples of 'reflective equilibrium'. They are examples, sure enough, of reflection and encouraging others to reflect, but what about the 'equilibrium'?

This only comes in when one is trying to bring particular cases, general moral principles, relevant empirical considerations etc together in a systematic and coherent way to provide a sound justification of an ethical claim. It is a philosopher's project, not one found in everyday life. As such, it belongs in the meta-ethical realm of controversy over the objectivity or otherwise of moral claims. If Tillson's teacher is simply encouraging reflection in a way familiar to those working in moral education, he or she is miles away from such fundamental philosophical theorising.

This is not necessarily to say that reflective equilibrium should have no place in schools. These are sometimes involved in teaching philosophy as well as moral education. I am thinking here of upper secondary students, not those in P4C classes in primary schools. The meta-ethical topic of reflective equilibrium is probably inappropriate as part of a philosophy curriculum for people new to the subject, but I do not want to rule it out. Perhaps a few of the smarter or more diligent members of a philosophy class may come across it, even get to grips with it. But these are not the learners that Tillson has in mind. He is talking about the moral upbringing of children in general like those waiting in his dinner queue.

A final concern I have about both Tillson's and Hand's positions is about indoctrination, in the sense in which Hand uses the term - a sense shared, I think, by Tillson. In 2002 Hand wrote

to indoctrinate a child (in the sense in which I am using this contested term) is precisely to impart beliefs to her in such a way that she holds them non-rationally, or without regard for the evidence. (Hand 2002: 546) 
There appear to be only two ways of imparting a belief to a person: by proving it to her or by indoctrinating her. One can appeal to her reason by presenting her with decisive evidence or argument; or one can bypass her reason by exerting psychological pressure on her. (op.cit: 546)

In a later work he said

[to teach children to subscribe to moral standards] in the face of controversy about the content and justification of morality appears tantamount to indoctrination.

(Hand 2014: 521)

For Hand, then, imparting a belief is indoctrinatory if this belief is held in such a way that it is not supported by decisive evidence or proven. If it is a controversial belief, the teaching cannot but be indoctrinatory.

Tillson would seem to follow Hand in this definition, to judge from his remark that indoctrination may sometimes be obligatory - if, for instance, the security forces could only check the threat from ISIL and jihadism by non-rational means. (p. [4])

Hand recognises that much of morality is controversial, but not all. The non-controversial area embraces several basic moral standards like prohibitions on stealing and cheating and prescriptions to treat others fairly and help those in need. Bringing children up to accept these standards can escape the charge of being indoctrinatory provided that there is decisive evidence supporting them. As has been said already, Hand finds such evidence in the Hart/Copp justification in terms of preventing social breakdown.

If Tillson is right in his critique of Hand's theory, a foundationalist account like the Hart/Copp justification will not do. That is why Tillson himself turns to reflective equilibrium as a sounder alternative. But Tillson's objection, coupled with the excursion I have just made into Hand's and Tillson's notion of indoctrination, seems to indicate a major difficulty for the whole enterprise in which the two writers are engaged and within which they have differing views.

The difficulty surfaces first in Hand's position. Only if the Hart/Copp justification is uncontroversial can moral education à la Hand be non-indoctrinatory. It is not enough for him to locate a set of uncontroversial moral standards like the prohibition on stealing: the rational backing for these must also be uncontroversial. But given that Tillson - as well as many other philosophers - has doubts about foundationalism, the Hart/Copp account cannot provide the uncontestable evidence that Hand requires. As a controversial claim, it makes Handian moral education an indoctrinatory enterprise in his terms.

This does not mean that Tillson himself is in the clear. Whether reflective equilibrium is a sound way of justifying moral claims is itself a position that only some hold. Hand - or any other foundationalist - would be among them. If reflective equilibrium is a controversial position (see also Daniels (2016), Section 4), there is at least a danger that leading students of moral education to see it as the proper way forward is an indoctrinatory move. I take it 
that this would be the last thing that Tillson would want, seeing it is the "broadly Handian conception of education' he holds ( $\boldsymbol{p}$.[2]) that has led him to enter the lists and try to delineate a conception of moral education (or enlistment) based on sound reasoning.

The above critique of both Tillson and Hand takes for granted the Handian account of indoctrination which they seem to share. But this account is problematic as it fails to bring out what is wrong with indoctrinating people. For Hand it is wrong because one is bringing another to believe something in the absence of good grounds for it. But if I am right that concern for people's well-being is a bedrock ethical attitude, one not based on further reasons, then trying to get learners to see that people's well-being is important in itself would, on a Handian view, be indoctrinatory and wrong.

I, on the contrary, see it as a necessary first step in moral education - not wrong at all, but pre-eminently desirable. For me indoctrination is not to do with imparting beliefs that lack good justification, but with imparting beliefs in such a way that they are likely to be hard to shake. What is wrong with indoctrination, whether it is of religious beliefs, political beliefs or beliefs in other areas - and whether it is by individuals or institutional (Taylor 2017, White (forthcoming)) - is that the fixedness of these beliefs is a threat to the learner's autonomy and hence his or her well-being. - And if you ask what is wrong with threatening someone's well-being, my answer is: here we reach bedrock. The spade turns no more.

In this paper I have looked at problems with Tillson's critique of my views; and I have looked at problems in Tillson's own position (as well as Hand's). As a concluding and I hope conciliating point, let me say that I strongly agree with Tillson - and perhaps with Hand that reflective discussion about ethical matters is educationally desirable, at least at an appropriate time and place. This applies to bedrock beliefs as well as others. It has to apply to them on my view of indoctrination, so as to lessen the chance of these being held in a way hard to shake.

Where I differ from Tillson on this issue of reflective discussion as he goes down his own path in the direction of reflective equilibrium, is over what the reflection is for. In my book, it should not be about seeking justification in an underlying theory. To come back to the basic belief that people's well-being matters, that it is something we should care about. It is an essential part of a sound moral education that learners should be encouraged to think about this. Central to their reflection should be thought and discussion about what human well-being is. This is far from being simply an academic matter. We live in a world where pressure from advertisers, social media and other sources leave many of us with inadequate or over-simplified ideas about what it is to lead a fulfilling life. To go into this in proper depth would require another paper, but perhaps I can assume agreement that whether a life of well-being is one in which such things as consumption, wealth, social recognition, worldly success, and bodily pleasures are conspicuous is at the very least controversial. Students should be encouraged to reflect on this, as well as on issues to do with the place in well-being of the satisfaction of basic needs (eg. for food, shelter, social recognition), 
personal autonomy, prioritising personal goals in the face of conflict. But their reflection on these matters takes them not towards an underlying justification, but towards getting clearer about the nature of well-being.

\section{References}

Daniels, N. (2016) 'Reflective equilibrium' Stanford Encyclopedia of Philosophy https://plato.stanford.edu/entries/reflective-equilibrium/

Hand, M. (2002) 'Religious Upbringing Reconsidered’ Journal of Philosophy of Education (30: 4)

------ (2014) Hand, M. (2014a) 'Towards a Theory of Moral Education', Journal of Philosophy of Education (48: 4)

Spiecker, B. and Steutel, J. (2001) 'Reflective equilibrium as a method of philosophy of education', in Heyting F., Lenzen D., and White J. (eds) Methods in Philosophy of Education London: Routledge.

Taylor, R. (2017) 'Indoctrination and social context: A system-based approach to identifying the threat of indoctrination and the responsibilities of educators'. Journal of Philosophy of Education (51: 1)

Tillson, J. (forthcoming) 'The Problem of Rational Moral Enlistment' Theory and Research in Education $(\bullet \bullet)$

White, J. (2016) 'Moral education and education in altruism. Two replies to Michael Hand' Journal of Philosophy of Education (50.3)

-------- (forthcoming) 'Indoctrination and Systems: a reply to Rebecca Taylor' Journal of

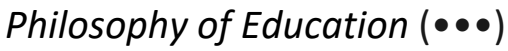

